\title{
Revision article
}

\section{Systematics and evolutionary biology: uneasy bedfellows?}

\author{
Sistemática y biología evolutiva: ¿compañeros incómodos?
}

\author{
Jeffrey H. Schwartz \\ Departments of Anthropology and History and Philosophy of Science University of Pittsburgh. Pittsburgh, PA 15217 USA \\ Correspondent:jhs@pitt.edu
}

\begin{abstract}
The history of systematics and evolutionary biology demonstrates how greatly the "modern evolutionary synthesis" instrumentally prevented, rather than facilitated, the intellectual growth and maturity of the diversity of evolutionary disciplines. In truth, the claim of the synthesis being synthetic is essentially without basis, indeed a myth. Instead, the "synthesis" had precisely the opposite effect: namely, squelching the arena of debate, disagreement, and diverse theorizing that had characterized the preceding decades. Although each of the 3 primary architects of the synthesis - Dobzhansky, Mayr, and Simpson - had his own agenda, they were united around the theme of population genetics and population thinking. When applied to systematics, especially by Mayr, the result can now be seen as confused at best. Perhaps this review will provoke a revival of earlier years of intellectual curiosity and fervor, and rekindle interest in systematic method and theory.
\end{abstract}

Key words: systematics, phylogenetic reconstruction, classification, developmental biology, modern evolutionary synthesis.

Resumen. La historia de la sistemática y de la biología evolutiva muestra el papel que tuvo la "síntesis evolutiva moderna" para impedir, en lugar de favorecer, el crecimiento intelectual y la maduración de la diversidad de disciplinas evolucionistas. En efecto, la pretensión de la "síntesis" de ser sintética carece de bases, y por ende, resulta un mito. En su lugar, la "síntesis" tuvo precisamente el efecto opuesto: suprimir escenarios de debate, acuerdos, y cancelar el desarrollo mismo de las teorías que caracterizaron las décadas precedentes. Aunque cada uno de los 3 estudiosos responsables de formular la síntesis -Dobzhansky, Mayr y Simpson- tenía su propia agenda, coincidían en torno al tema de la genética de poblaciones y el pensamiento poblacional. Sin embargo, el resultado del debate respecto a la sistemática, especialmente abordado por Mayr, es actualmente confuso en el mejor de los casos. Quizás esta revisión provoque un resurgimiento en el fervor y la curiosidad intelectual de los primeros años, e incremente el interés en la teoría y el método sistemático.

Palabras clave: sistemática, reconstrucción filogenética, clasificación, biología del desarrollo, síntesis evolutiva moderna.

\section{Systematics (and paleontology) came first}

The pursuit of systematics preceded by centuries any inklings of thought that could even loosely be considered evolutionary in nature (see review in Schwartz, 1999). Indeed, the motivation for constructing taxonomies or classifications on the basis of comparative anatomy was provoked by the antithesis of evolutionary thought: creationism and the Great Chain of Being (Lovejoy, 1942). Consequently even though the present-day classificatory system retains Linnaeus' (Linnaeus, 1735)

Recibido: 02 julio 2009; aceptado: 10 agosto 2010 clarification and fundamental combination of Konrad Gesner's (Gesner, 1551-1558) vaguely defined category "genus" with John Ray's (Ray, 1693) variably more concrete notion of "species", its existence derives from the history of attempts by diversely schooled and unequally perceptive systematists (taxonomists) to "divine" the one scala naturae that reflected the true sequence of creation by a divine being (Schwartz, 1999). This history notwithstanding, the attempts of these early systematists to decipher an interrelationship among organisms via an eye toward anatomical detail provided the foundation for the eventual transformation of biology from a spiritual experience based on revelation and scripture to a scientific endeavor to reconstruct the evolutionary history of life 
(Schwartz, 1999).

Of further importance in this brief historical overview is the fact that, as with fossils, the reality of fossils as onceliving organisms and the discipline of paleontology this acknowledgement spawned also occurred centuries before the reality of evolution was recognized by naturalists and comparative anatomists (Schwartz, 1999). For discussion here, it is relevant not only that non-human organisms were "allowed" to have a past history - albeit one that was interpreted in the context of the creation story in which humans were not (appreciably) antediluvian but also and perhaps more critically that the discoveries of paleontologists provided systematists with myriad new life forms they could insert into the classificatory representations of their perceived Great Chains of Being. Further, not only were fossils now seen as affording additional evidence of divine acts of creation, but these "petrifications", even if often fragmentary, were seen as providing evidence that life in the past was no less diverse than in the present (Schwartz, 2006a).

Penecontemporaneous with the earliest seminoncreationist biological thinkers - especially the transformationist, Lamarck - the French paleontologist, comparative anatomist, and committed creationist who encapsulated his religious and scientific beliefs in a "theory of catastrophes," Georges Cuvier, broadened the horizons of systematics by applying in analogy the behavior and ecology of living animals to reconstructing the lives and ecological settings of morphologically similar but extinct species (Haeckel, 1868; Gregory, 1910). Indeed, Cuvier was so convinced of the correctness of his powers of extrapolation, he bragged that he could construct an entire animal and its behavior from a footprint alone (Haeckel, 1868; Gregory, 1910). Also in this claim Cuvier revealed his preference for imbuing the "essence" of an animal in its feet, which provided the window on its locomotory behavior, the structures and configurations of which he emphasized over dental morphology (which would reflect dietary behavior) in his classifications of vertebrates (Gregory, 1910). Thus, while we see the beginnings of a kind of "adaptive thinking" in the transformationist-use/ disuse writings of Lamarck and subsequently of Darwin - that is, the organism is playing "catch-up" with its ever-changing environment - we can, I believe, read into the biblically informed musings of Cuvier a concept of adaptation that links the organism immediately and directly with its ecological circumstances. In either case - and bearing in mind that one concept derives from a transformationist model, while the other reflects a static model - the discipline of systematics now encompasses notions of "adaptation" and "adaptive traits".

\section{Wither systematics in the formulation of evolutionary thought?}

Given the prior history of systematics it is noteworthy that the individual with whom evolutionary thought is most widely associated, Charles Darwin, did not bring systematics and evolutionary theory together. True, he did produce volumes on the systematics (or at least classification) of barnacles and moulds, and in numerous letters he did agonize over whether a particular specimen of plant or animal represented a "variety" or a "species" (Darwin, 1903). But he neither tackled head on the problem of species identification - preferring to fall back on the belief that experienced taxonomists somehow know a species when they see one - nor generated a systematic or taxonomic overview of animals or plants or, within the former, of vertebrates, invertebrates, or even mammals, as did contemporary evolutionists, especially the saltationists Thomas Huxley (Huxley, 1863b, 1869, 1880) and St. George Mivart (Mivart, 1864, 1868, 1873, 1882). This seems odd in light of Darwin's discussion as early as the first edition of the Origin of the role of classification in reflecting genealogical relationships (Darwin, 1859). Perhaps his inability or indifference to intertwining systematics and evolutionary theory was rooted in the fact that he was not a practicing comparative morphologist, but instead relied on scientific publications as well as anecdotal information of others.

Indeed, in the only post-Origin publication in which he presented an argument for the evolution of actual groups of organisms, The Descent of Man, Part I, Darwin (Darwin, 1871) cites only the work and conclusions of others - particularly Huxley - in reviewing (albeit myriad) anatomical details that would nest humans within vertebrates, within mammals, and specifically within the order Primates. But when it came to discussing the evolution of "man", he abandoned altogether the realm of comparative morphology, on the basis of which Huxley had kept humans and a group consisting of the 3 large-bodied apes well apart by allocating the 2 to 2 different families. Here, Darwin fell back on 2 of his major assumptions (Schwartz, 2005a): namely, that the ancestor of closely related species should be found in deposits in the same geographic area in which its descendents now live, and that the kinds of selection pressures necessary to transform an apelike ancestor into an animal as distinctive as a human - particularly in being small yet bipedal and large brained - would be available only in the most "dangerous" parts of the world, the Arctic and Southern Africa.

Since humans exist virtually everywhere on earth, and large-bodied apes are found both in Southeast Asia (the orangutan) and in tropical sub-Saharan Africa (the 
chimpanzee and gorilla), the critical factor in Darwin's deciding which ape or apes were most closely related to Homo sapiens, and thus in which continent one would expect to find their common ancestor, was the environmental setting. For as he imagined it, the lush tropical evergreen rainforests of Southeast Asia would not have provided the dangers that Southern Africa would, with its large predators and arid environment. Consequently, Africa must have been the seat of human-ape ancestry and therefore the African apes must be the closest living primate relatives of $H$. sapiens (Schwartz, 2005a).

While Alfred Wallace (Wallace, 1898), whose experiences living with "primitive" people convinced him of their intellectual equality with "civilized" people and thus that the process of natural selection was involved only in the origin of $H$. sapiens and not in continually transforming the species, Darwin (Darwin, 1871) believed otherwise. For him, as many chapters in Part I of The Descent are titled, there was an evolution or transformation from primitive to civilized "man" that was abetted by the relentless forces of natural selection as well as by processes of sexual selection, the discussion and elaboration of which consumes the remainder of The Descent. With this in mind, it therefore becomes reasonable to read Darwin's case for human origins being African as a reflection of the fact that while "high" civilization had existed for centuries in Asia, Africa retained some of the most "primitive" humans on the face of the earth. Furthermore, these humans happened to be black, as are the African apes (although this is primarily because of their pelage). In this framework, the fact that the living African apes occupy some of the densest and most lush tropical evergreen forests in central Africa becomes secondary to the continent as a whole, in whose most southerly (and also easterly) regions one finds the perils which Darwin invoked as the critical provocation for the emergence of our species.

In contradistinction to Darwin, we see especially in chapter 2 of Huxley's (Huxley, 1863c) Evidence as to Man's Place in Nature the combination of comparative morphology, embryology, and systematics. This chapter - "On the Relation of Man to the Lower Animals" - is particularly significant because it was the first work after Linnaeus (Linnaeus, 1735) classified humans in the order Anthropomorpha (which in 1758 he changed to Primates) that not only defended this "heretical" proposition, but also argued that Homo sapiens should be classified in a particular subgroup of primates with the apes. Further, by beginning this chapter with a demonstration that humans shared first and broadly with vertebrates (via chick, reptile, dog, and monkey), then with mammals more specifically (dog and monkey), and even more so with primates (monkey) a common ontogeny, Huxley centralized the study of development both as a foundation from which to proceed with the more common approach of comparing the morphologies of adult individuals and as an area of investigation essential to taxonomic and thus systematic endeavors.

By embracing von Baer's (von Baer, 1828) precedent that when comparing ontogenies one is only comparing pre-adult (e.g. embryonic, fetal, larval) individuals prior to the emergence of the species-specific morphology of the adult, Huxley echoed the focus of fellow saltationists: namely, that the potential for evolutionary significant change must lie in altering early phases of development, not in the selection of features that are already committed to develop into their adult form (Schwartz, 2008, 2010). In the saltationist rejoinder to Darwin's Origin - On the Genesis of Species - Mivart (Mivart, 1871) adapted to a model of the origin of organismal novelty Galton's model of the emergence of different crystalline shapes, in which one geometric form "changed" into another by "flipping" from one state of equilibrium to another, without passing through minute intermediate stages. By analogy, Mivart suggested, the potential for evolutionarily novel morphology must derive from a dramatic alteration of development that produces a state of developmental, physiological, and morphological equilibrium - with a new ontogenetic outcome - in descendants (i.e. offspring) that subsequently differed from the state of developmental, physiological, and morphological equilibrium of their ancestors (i.e. parents) (Schwartz, 2005c).

Mivart, however, addressed neither the question of the relative "success" of such major episodes in developmental reorganization nor the problem of more than one individual bearing the novelty. And unfortunately, by not doing so, he exposed himself to Darwin's (Darwin, 1872) retort that the saltationist model exceeded the limit's of credulity to expect that more than one individual (and of opposite sexes) with a profoundly different morphology than the parents would "spring" into existence - which, of course, was minimally necessary for this hypothetical new species to persist. [Interestingly, Dobzhansky (Dobzhansky, 1941) would levy a similarly harsh criticism on Goldschmidt (Goldschmidt, 1940) with regard to "hopeful monsters".]

It might be too lenient a reading of Mivart to suggest that he may not have thought it necessary to discuss the relative success of major revolutions in development because the myriad examples he mustered in rebutting the notion that a functionally important feature could emerge only through the gradual accretion of minute variations were those that had reached a new equilibrium and therefore did exist. In other words, the developmental upheaval that produced such wildly different morphologies as "horns" in beetles, the side-by-side positioning of eyes in flatfish, 
the mammary glands of mammals, or the beaks of birds had "worked". Nevertheless, for the discussion here, it is important to recognize that by centralizing developmental reorganization as the basis for evolutionary change, the saltationists were in diametric opposition to Darwin, not only in rejecting the notion that evolution is a process of smoothly gradual transformation over long periods of time, but also in rejecting the notions that natural selection and use/disuse were relevant to a discussion of the evolution of novelty (Schwartz, 2001; Schwartz, 2005c).

The latter point is particularly compelling because it highlights how Darwin differed from the saltationists in his appreciation of development. That is, although as early as the first edition of the Origin Darwin remarked on the importance of development for evolutionary discourse, it is clear from his emphasis on the effects of use/disuse - which he incorporated into his theory of inheritance, pangenesis (Darwin, 1868) - together with natural selection favoring the most advantageous variation, that his focus was the "postnatal" individual (Schwartz, 2005c;Schwartz, 2010). Indeed, since Darwin's conception of natural and then also sexual selection is their action on features that already exist, the entity upon which they act must be a fully formed adult or at least an individual whose development was committed to an ontogenetic pathway that would lead to specific adult morphologies. The case with regard to use/ disuse is even more self-evident. For an individual must be functioning and exposed to the whims of circumstance before life experiences could impress themselves upon the biology of that individual and, according to the theory of pangenesis, introduce new types of gemmules into the potential reproductive mix of offspring.

Darwin's focus on the "postnatal," essentially adult individual is also reflected in his conception of intermediates, of which the fossil Archaeopteryx, with teeth and other "reptilian" features in combination with a feathered, quasi- birdlike body, is offered as the prime example. Discovered in 1861, Darwin (Darwin, 1872) centralized Archaeopteryx as proof of his model of smoothly gradual evolutionary change via a succession of minutely differing intermediate stages, seeing in this extinct vertebrate a form that lay somewhere in between the states of being completely reptile and completely bird. Indeed, in his rebuttal of Mivart - for which he produced the sixth and last edition of the Origin - Darwin (Darwin, 1872) used the "obvious" intermediacy of Archaeopteryx as one of the supposed crushing blows to his rival's saltationist thesis. Mivart (Mivart, 1871), however, interpreted Archaeopteryx differently:

But even supposing all that is asserted or inferred on this subject to be fully proved, it would not approach to a demonstration of specific origin by minute modification. And though it harmonizes well with 'Natural Selection,' it is equally consistent with the rapid and sudden development of new specific forms of life. (p. 131)

It is significant that Mivart questioned the assumptions that would give credence to declaring any specimen an "intermediate" form and from that position assume that one could extrapolate into the still very real and omnipresent gaps in the fossil record a succession of everso-slightly differing intermediates between the declared "intermediate" and the 2 points - quite different "ancestor" and "descendant" - between which it is supposed to have resided evolutionarily. For after all, it is we who bestow upon forms such as Archaeopteryx the "property" of intermediacy according to our preconceptions. Further, Mivart was also correct in pointing out that even under the presumption that one might have demonstrated the "intermediacy" of any specimen between 2 presumed end points, one has not demonstrated how that "intermediate" form actually came into being, whether gradually, saltationally, or in some other manner.

Although Mivart's criticism was directed at an unwarranted scenario of evolutionary change involving an extinct taxon, in this case Archaeopteryx, one can, I would argue, extend this appreciation to include extant taxa because, upon reflection, the picture of diversity of extant taxa is just as static as that provided by the fossil record. That is, in reality, observations on the physical and other attributes, as well as on the biogeographic distributions, of extant taxa record only a snapshot of a particular point in time. They are not demonstrations of how the different morphologies and spatial distributions of extant taxa came to be as they now are. Even the oft-cited studies of Darwin's finches are merely descriptions of facts collected over a number a years (Grant, 1999; Grant and Grant, 2008). This is data. The explanation of how and why populations of birds with different bill shapes fluctuated during that time is not.

To begin with, the latter kind of evolutionary explanation assumes an unproven correlation between form and function that, while fundamental to Darwin and then the synthesis' and post-synthesis' versions of Darwinism, was rejected by Darwin's contemporaries, the pre-Morgan Mendelians, and other evolutionists of the $20^{\text {th }}$ century. For these non- and, in some cases, anti-Darwinians, evolution was not adaptation writ large. Rather, the mechanism/s that lead to morphological novelty (and thus potentially new species) is distinct from that underlying the persistence of the novelty (and thus the survival of the species) (Schwartz, 1999, 2001). Features do not emerge because they confer an advantage, but once in existence certain variants or 
expressions of a feature may confer to their bearers greater advantage (or reproductive success) than other variants or expressions of it (Schwartz, 1999, 2001).

To illustrate, is it relevant to ask, "Are antlers more selectively advantageous than feathers?" or even "Is tining of white-tailed deer antlers more advantageous than span of moose antlers?" Yet it might be reasonable to ask, "Do different patterns or expressions of white-tailed deer or of moose antlers confer different selective advantages to their bearers?" This kind of speculation aside we are still, however, at square one in terms of addressing the questions, "How did antlers, how did major configurations of antlers, and how did different within-species antler configurations come to be?" The observation that some artiodactyls have antlers, that groups of antlered artiodactyls have different antler configurations, and that individuals within any particular group of antlered artiodactyls express variations of their species' antler configuration does not inform about the developmental processes or evolutionary mechanisms that underlie this hierarchy of difference.

The contrarian, however, would probably respond that fruit-fly experiments, beginning with Morgan's (Morgan, 1916, 1922; Morgan et al., 1926), have consistently demonstrated that novel features must arise through the ploddingly slow accumulation of minuscule changes. For after all, was there not general acceptance decades ago of Morgan's (Morgan, 1916, 1922; Morgan et al., 1926) argument that it would be too disruptive to the biological integrity of organisms if the genetic changes underlying morphological change were large and abrupt? Nevertheless, that rebuttal is at best tautological and in reality false.

I do not mean to suggest that Morgan and colleagues (Morgan et al., 1926) did not document myriad instances of the abrupt loss of major structures (e.g. eye, wing, thoracic segment) or the occasional abrupt appearance of novel forms (in particular, bithorax). But it was only by injecting into the equation his "feeling" about what would and would not work evolutionarily that Morgan denied any reality in nature to the abrupt, large-scale change he observed in the laboratory between parent and offspring. And this assumption is in direct contradiction of his earlier argument that experiments and observations in laboratory colonies of fruit flies do serve as examples of what actually occurs in nature (Schwartz, 2006b). In addition, even the observed small-scale changes (e.g. eye color, thoracic bristle number) came and went from one generation to the next as discrete entities. Nevertheless, having come to the unjustified conclusion that large-scale changes would interfere with the viability of their bearers - in spite of the fact that in his laboratory such creatures were perfectly viable and bred successfully among themselves and with individuals of the parental type - Morgan could then claim that the only mode of change that would "work" in nature would come from minute genetic changes that produce minuscule morphological differences between parents and offspring (Schwartz, 2006b).

The "proof" that this could and would happen was seen by Morgan as having been demonstrated by an experiment in which one of his collaborators, Sturtevant, selectively bred from each generation of fruit flies individuals with wing lengths that were increasingly shorter. Eventually, this skewed the modal distribution of wing length from the typical condition of wings being slightly longer than body length to wings that were shorter than body length (Morgan et al., 1926; Morgan, 1935). There still were, of course, individuals with relatively long as well as relatively short wings. Nevertheless, the extrapolation from this experiment was that if selective breeding were to continue long enough, a population of wingless fruit flies would be established. But it never happened. Similarly, no population genetics experiment has ever produced a fullblown novel trait from structure that in hindsight one might assert was "incipient." The only experiments that produce full-blown "novelty" are those that create phenocopies but, when these individuals interbreed, the original and not the novel form is produced (Waddington, 1957).

As I discussed elsewhere (Schwartz, 2005c), a similar myopia with regard to what "works" in non-natural settings (in this case, arenas of domestication) versus what will be viable in nature informed Darwin's (Darwin, 1868) rejection of "monstrosities" and "sports of nature" as reflections of natural processes. Indeed, his stance on "monstrosities" and "sports" is even more wonderful because he was fully aware of numerous examples of a new "sport" or "monster" that appeared suddenly in a generation and was then bred successfully with individuals of the "normal" type in order to establish a new breed of plant or animal [e.g. the flowering Brussels sprout and Niata cattle (Darwin, 1868; Morgan, 1903)]. Darwin justified this rejection via the belief that these artificially created yet completely viable and reproductively competent individuals would not be able to adapt to climatic or other environmental changes and thus cannot be seen as examples of what could occur in nature.

True, it is unlikely that fat-tailed sheep (which require that the shepherd lifts the tails of the females so they can mate) would survive in nature. But it is only the Darwinian bias toward selection of the most "advantageous" traits that leads one to this conclusion. From a saltationist or any non-Darwinian perspective, however, the emphasis is not on the survival of the "fitter" or "better adapted". Rather the emphasis is on the survival of the "fortunate," the "lucky," and the "average" (Morgan, 1903; Schwartz, 1999). Thus the very examples of "sports" and "monsters" that became 
the progenitors of entirely new breeds that Darwin rejected as providing insight into biological reality became a cornerstone in the saltationist model of rapid evolutionary change (Schwartz, 2005c). If the feature did not interfere with the viability of its possessors - which clearly a grossly oversized and fat-heavy tail would in preventing sheep so endowed to reproduce - it persisted. Once established the novel feature could vary, natural selection could act on this variation, and that was that (Huxley, 1860; Mivart, 1871; Huxley, 1876; Bateson, 1894; Morgan, 1903; de Vries, 1910a, b; Goldschmidt, 1940). Perhaps, then, it is not surprising that Huxley and Mivart, and originally Bateson, were themselves systematists, not only in the pursuit of determining evolutionary relationships and producing classifications, but also in centralizing development in their endeavors.

\section{Systematics and the "Modern Evolutionary Synthesis"}

While the late $19^{\text {th }}$ and early $20^{\text {th }}$ centuries witnessed debate and altercation between different schools of evolutionary thought - first saltationists versus Darwinians, followed by Mendelians versus Darwinians, and then rapid versus gradual transformationists (Schwartz, 1999) - systematists stayed intellectually to themselves. This was, I believe, due in large part to the fact that one could do systematics - name new genera and species, compare morphology, produce different classifications - without the burden of any particular model of evolutionary change. Even the vertebrate paleontologist Henry Fairfield Osborn's (Osborn, 1934) theory of "aristogenesis" [a version of orthogenesis (Jepsen, 1949)] did not intrude upon this activity. This was possible because seeing evolution as a "goal-oriented" or "purpose-driven" process could stand alone since it was a direct outgrowth of the general notion in paleontology that one could read evolutionary history from the chronological sequences of fossils. Consequently, the best way in which to reveal the history of life was through exploration for and discovery of new forms - activities that preoccupied both paleontologist and neontologist alike. It mattered less that a particular trait emerged gradually or in the space of a generation than that the diversity of life, both present and past, was sampled as thoroughly as possible in order to divvy it up into smaller and smaller groups of increasingly similar (and thus for some systematists also increasingly closely related) organisms.

From this perspective, in which revealing the historical picture that evolution left in its wake depended on increasing knowledge of taxic diversity, it may seem an oxymoron that a major figure in the attempt to define "species" the lynchpin of systematics - was a fruit-fly population geneticist and one of the architects of the so-called modern evolutionary synthesis, Theodosius Dobzhansky. Indeed, his work on the effects of chromosomal rearrangement on fecundity had led him to entertain more broadly the matter of what a species is, how it forms, and how a taxonomist might identify it. In his first theoretical attempt to address the species concept, Dobzhansky (Dobzhansky, 1935) cited Bateson for recognizing that while defining "species" is difficult, taxonomists know that difference between species is something more than a matter of degree, and for acknowledging that discontinuous, not continuous, variation typifies life. Further, that the "manifest destiny of life [is] toward formation of discrete arrays" (p. 347), and that it was the natural discreteness of living forms that made it possible for a taxonomist to identify species with some confidence.

Reminiscent of Fisher's (Fisher, 1930) assumption that species are typically geographically widespread and that some factor or instability leads to a fissioning that eventually yields daughter species, Dobzhansky (Dobzhansky, 1935) attributed the beginning of speciation less to geographic than to physiological isolation. He hypothesized 2 major kinds of physiological isolating mechanisms: those that led to potential mates becoming reproductively incapable of producing viable hybrid offspring, and those that produced sterile hybrid offspring. Dobzhansky conceived numerous examples for each category of physiological isolating mechanism, including intersexuality in hybrid offspring, which was based on Goldschmidt's (Goldschmidt, 1934) work on the gypsy and nun moths of the genus Lymantria. In practical terms for recognizing that speciation had occurred, regardless of the specific physiological isolating mechanism, the resultant daughter species would not be able to interbreed.

In 1937, Dobzhansky expanded his ideas on species and species formation in Genetics and the Origin of Species. But while continuing to emphasize physiological isolating mechanisms and discontinuous variation - because the very Mendelian nature of genes implied discrete genetic units and thus discrete morphological traits - his conception was no longer Batesonian but, perhaps because he had taken a postdoctoral position in Morgan's laboratory, it was clearly Morganian. That is, Dobzhansky envisioned the differences between discrete units and traits as being so insignificant "that if we could assemble all the individuals which have ever inhabited the earth, a fairly continuous array of forms would emerge" (p. 7). And further, "that all these changes have taken place due to causes which now continue to be in operation and which therefore can be studied experimentally" (ibid.). In other words, while one could not witness the emergence of a new species, because the entire process - which Dobzhansky referred 
to as macroevolution - exceeds a human lifetime by hundreds of thousands if not millions of years, the tenet of uniformitarianism allows one to study the fundamental processes of evolution through population genetics by observation and experiment on the "assumption" (p. 12) that the mechanisms of macroevolution (the emergence of species) and microevolution (the small genetic and thus phenotypic changes that cumulatively create a different species) are aspects of the same continuum.

Although he embraced mutations of individual alleles and their accumulation as potentially leading to change, Dobzhansky maintained that chromosomal rearrangement played an even more significant role because of the spatial aspect of gene interaction. That is, because spatial reorganization through chromosomal rearrangement would affect some number of different kinds of genes, their functions would also be altered. This, then, would provide a continual source of variation that would continually stoke the engine of evolutionary change. As Dobzhansky saw it, a "species that would remain long quiescent in the evolutionary sense is likely to be doomed to extinction" (p. 79). Yet, given his emphasis on chromosomal difference underlying eventual species difference, it is interesting that while he acknowledged that in certain plants intergenerational genetic change through polyploidy resulted in significant morphological change in offspring, he denied to animals the possibility of abrupt and significant intergenerational morphological change. The latter presumption was also used by Mayr (Mayr, 1942) and even Simpson (Simpson, 1944) in their rejection of any saltational, and thus non-Darwinian (in the gradualistic sense), theory of evolutionary change.

Dobzhansky's (Dobzhansky, 1941) conversion to hard-core Darwinism and his virtual abandonment of chromosomal rearrangement as the primary genetic source of variation was provoked by the developmental geneticist Goldschmidt's (Goldschmidt, 1940) The Material Basis of Evolution. In that monograph, Goldschmidt invoked chromosomal rearrangement as a potential source of major genetic change that would underlie major or systemic change that, in turn, would produce rapid and abrupt evolutionarily significant change: that is, the origin of species. As a developmental geneticist Goldschmidt argued that there was a difference between the kinds of effects experiments in fruit-fly population genetics generated and those that would produce significant organismal change. Although his thesis emphasized single major developmental and thus organismal "leaps", Goldschmidt did allow that the final "product" may also be the result of a series of systemic mutations with smaller developmental consequences to each successive species.

Echoing and also building upon the theoretical position of Victorian saltationists as well as Bateson, de Vries, and the early Morgan, Goldschmidt distinguished between the population-genetics-based mechanisms (micromutation) that produced variation within a species (microevolution) and other mechanisms (macromutation) that led to the origin of species (macroevolution). He dubbed the bearers of these systemic mutations "hopeful monsters" (in obvious reflection of the $19^{\text {th }}$ century meaning of "monster" or "monstrosity"), which would be taken out of context and incorrectly characterized by his detractors - Dobzhansky, Mayr, and Simpson - and then used against him in their slurs of denigration.

In the first edition of Genetics and the Origin of Species Dobzhansky (Dobzhansky, 1937) cited positively Goldschmidt's (Goldschmidt, 1934) studies on intersexuality in gypsy and nun moths. But when he (Dobzhansky, 1941), Mayr (Mayr, 1942), and Simpson (Simpson, 1944) focused their attacks on Goldschmidt's theory of systemic evolution they overlooked, and by dint of denigrating Goldschmidt, caused to be submerged the latter scholar's discussion of the interplay of genetics and development, particularly the timing of induction, threshold effects, and the regulation of development topics that are central to evolutionary developmental biology today. That Dobzhansky at least could not see past his anger to appreciate Goldschmidt's insight might seem surprising, especially since his conception of the effects of chromosomal rearrangement - incorporating Wright's notion of new gene combinations and interactions rather than mutation being the sole generator of novelty - and his emphasis on isolation via physiological mechanisms, suggests a potential appreciation of "development". Clearly this was not the case. Rather, and in acknowledgement of de Beer's (de Beer, 1930) rejection of population genetics as providing a window on evolutionary processes, I suggest that it was Dobzhansky's focus on the first 2 cell divisions and the distributions of genes (and the consequent conception of a direct translation of genes into adult morphology) that made him intellectually blind to Goldschmidt's developmental perspective. Thus, in the second edition of Genetics and the Origin of Species (Dobzhansky, 1941), while expanding his discussion of population genetics and affirming that evolutionary change was typically gradual, most of the revision consisted of the addition of numerous, basically ad hominem, assaults on Goldschmidt and his theory of systemic mutation (Schwartz, 1999).

Curiously, Dobzhansky (Dobzhansky, 1941) did not mention a volume, The New Systematics, edited by Julian Huxley (Huxley, 1940b), that had been published the previous year. In contrast to the 3 volumes that underpinned the "modern evolutionary synthesis", the 
topic of taxonomy and systematics preoccupied most contributions to The New Systematics, whether neo- or paleontological, zoological or botanical. Consequently, this collection distinguished itself from Mayr's (Mayr, 1942) Systematics and the Origin of Species, in which discussion of taxonomy and "doing" systematics occupied very few pages indeed. While the emphasis in The New Systematics may remind us of Dobzhansky's 1935 article on the species concept and taxonomy, it serves better to illustrate that J. Huxley and contributors (who were primarily British because, as Huxley states in the Foreward, his intention was to facilitate communication between them) endorsed the perspective that it was only through discourse across a diversity of disciplines, not through inference from population genetics alone, that questions concerning the nature of species could be addressed intelligibly.

The New Systematics is further distinguished from the volumes that gave us the "synthesis" in that, in J. Huxley's introductory chapter and of course in de Beer's chapter (de Beer, 1940), discussion of development and of the multitude of factors (internal and external to the organism) that influence development encompasses both systematics and evolutionary processes. Although Huxley did not cite Goldschmidt in this publication, he did so on numerous occasions throughout his monograph, Evolution: The Modern Synthesis (Huxley, 1942). Indeed, in the preface he acknowledged the valuable contributions to his work of "Dobzhansky, Waddington, and Goldschmidt" (p. 7) and later commented, "Equally obvious is my debt to the Morgan school and to Goldschmidt; but clearly this would apply to any modern book dealing with evolution" (p. 8). Equally obvious in retrospect is the fact that in the latter sentiment Huxley was dead wrong, at least with regard to Dobzhansky, Mayr, and Simpson and, consequently, the inheritors of their "synthesis". The difference between Huxley and Dobzhansky (and his mimics Mayr and Simpson) is that the former scholar was able to dissociate the validity and value of Goldschmidt's experimental work in developmental genetics from his theory of evolution by systemic mutation, whereas the latter individual could not or perhaps chose not to do so.

Might Dobzhansky have become further committed to his conception of species formation because he had not been invited to the conference from which this volume emerged? Perhaps it was because of Huxley's emphasis on the primacy of selection rather than isolation as the provocateur of species formation, which was in direct opposition to Dobzhansky's (Dobzhansky, 1941) and subsequently Mayr (Mayr, 1942) and Simpson (Simpson, 1944) conception of isolation (typically geographic) followed by selection. Or might it have been the following statement (Huxley, 1940a)?
Dobzhansky (1937) has drawn attention to the fact that they [species] are the most stable units in taxonomic practice, as compared either with infra-specific categories such as variety or subspecies, or supraspecific ones such as genus, subfamily, or family. When, however, he tries to define the species-level as that stage in taxonomic differentiation after which fertile interbreeding is impossible, he goes far beyond the facts. It is certainly right to attempt a dynamic, in place of a static, definition by thinking of subspecies and species as stages in a process of evolutionary diversification: but it is impossible to insist on infertility as the sole criterion of this stage. Many groups, especially among plants, universally recognized as species by taxonomists, are capable of fertile intercrossing, and in many others we find sterility between mere strains of obvious species. Thus either Dobzhansky's definition is untrue, or, if true, taxonomic practice must be so re-cast as to rob the term species of its previous meaning. (p. 16-17)

Whatever the actual reason, it is clearly the case that the authors of the "American" modern synthesis were anything but synthesizers. Indeed, even though each represented a different biological discipline, Mayr the systematist and Simpson the paleontologist subordinated their fields to Dobzhansky's population genetics. On the other hand, those scholars, whom these 3 criticized, chastised, pilloried, or just plain ignored (and who did not reside in the United States) were at least attempting to be synthetic. In this regard, it is perhaps telling that Dobzhansky's (Dobzhansky, 1941) only discussion of systematics in the second edition of Genetics was to lump it with morphology and then dismiss them both as being "predominantly descriptive and observational disciplines, [which] took precedence among biological sciences during the eighteenth and nineteenth centuries" (p. 6). In contrast, however, Dobzhansky writes of his own discipline: "Genetics being a branch of physiology concerned in part with the problem of organic diversity, is a nomothetic (law-creating) science" (p. 7).

What an historical irony it is then that those who acknowledge J. Huxley as the author of the phrase, "the modern synthesis", do so as if he had coined it specifically to characterize Dobzhansky's brainchild. In reality, however, Huxley's endeavors represent a real attempt at synthesizing a diversity of biological realms, while Dobzhansky's unidimensional and unilateral melding of Darwinian notions of gradualism and selection with interpretations of experiments in population genetics won out and consequently became the constraint under which a diversity of biological disciplines were intellectually incarcerated and forced to operate. Thus, and in spite of 
Dobzhansky's (Dobzhansky, 1941) seemingly synthetic declaration that "the present aim of the book is to review the genetic information bearing on the problem of organic diversity, and, as far as possible, to correlate it with the pertinent data furnished by taxonomy, ecology, physiology, and other related disciplines" (p. 7) (but not, however, morphology or the "purely morphological aspect of the problem" of organic diversity), it is difficult to gloss over what he really believesd: namely, that the genetic tail not only wags the biological dog, but also determines what is correct and what is not in evolutionary thinking and thus the shape of the rest of it. As he informs the reader in the first of many iterations of this theme, "it remains true that genetics has so profound a bearing on the problem of the mechanisms of evolution that any evolutionary theory which disregards the established genetic principles is fault at its source" (p. 9).

It is therefore with the second edition of Genetics and the Origin of Species that I situate the beginning of the "modern evolutionary synthesis" and its ideological entrenchment in a particular melding of Darwinism and population genetics. And, to paraphrase de Beer (de Beer, 1930), with the solidification of this one particular ideology, the focus in evolutionary biology was shifted intractably to the mechanism of transmission from parent to offspring of the genes that were thought to underlie traits and their variations, as if these were the only elements necessary to understand evolution and the origin of evolutionary novelty. Lost or at least missing entirely from this perspective was any appreciation of development. To use the terminology of especially Mivart, de Beer, Goldschmidt, and Schindewolf (Schindewolf, 1936, 1993) and also to acknowledge the intent of Bateson (Bateson, 1894), D'Arcy Thompson (Thompson, 1917), and Waddington (Waddington, 1940), also absent was any interest in or understanding of the "internal factors" that together act and interact to produce novel morphologies, potentially significant evolutionary change, and perhaps then species, which at base remain the centerpiece of systematics.

It is thus in this mindset - of so-called "population thinking," meaning understanding evolutionary processes through the study of populational variation and the transmission of its genetic underpinnings - that Mayr (Mayr, 1942) and Simpson (Simpson, 1944) reinforced the dogma of what became the "modern evolutionary synthesis". Consequently, while the practice of systematics had historically been concerned primarily with allocating specimens to named genera and species, erecting new taxa, and sometimes generating statements of evolutionary relationship, Mayr's systematics now focused on "species" through the lens of populational variation as the prelude to change within a species as well as to the splitting of a species into daughter species. As such, while the conception of the species as an actual biological entity was still discussed, the emphasis was now on a particular process that led smoothly, continuously, and seamlessly from the formation of a species through its persistence, all the while in a state of continual transformation, rather than on how to identify it. Indeed, Mayr's (Mayr, 1942) biological species definition is linked inextricably to the notion of a process:

A species consists of a group of populations which replace each other geographically or ecologically and of which the neighboring ones intergrade or interbreed where they are in contact or which are potentially capable of doing so (with one or more of the populations) in those cases where contact is prevented by geographical or ecological barriers.

Or shorter: Species are groups of actually or potentially interbreeding natural populations, which are reproductively isolated from other such groups. (p. 120)

And the process is conceived thusly (p. 159):

That speciation is not an abrupt, but a gradual and continuous process is proven by the fact that we find in nature every imaginable level of speciation, ranging from an almost uniform species at one extreme to one in which isolated populations have diverged to such a degree that they can be considered equally well as separate, good species at the other extreme. I have tried in a recent paper...to analyze this continuous process...A widespread species is more likely to represent the first stage of speciation than one with a narrowly restricted range.

In 1949 Mayr (p. 285-6) (Mayr, 1949) states unequivocally, "A steadily increasing amount of evidence has accumulated to show that speciation normally is gradual...It was shown by me in a previous publication (Mayr, 1942) that all this evidence indicates that the normal process of gradual speciation is that of geographic isolation". Yet, in apparent contradiction to this declaration, Mayr (Mayr, 1949) acknowledges that "the origin of a new species of higher animals in a human life span is impossible; in fact, it may require a minimum of about one-half million years, and normally even considerably more than that" (p. 286). Dobzhansky (Dobzhansky, 1937; Dobzhansky, 1941) had also recognized this as a consequence of embracing a gradual tempo of change. And in turn, this had led him to argue that even though speciation was a prolonged process of gradual intrapopulational change, insight 
into the process of species formation could nonetheless be achieved by experimentally studying the genetics of populations from one generation to the next. Mayr, on the other hand, seems to have become so convinced of his ability to "identify evolution in progress" that he could claim that he had evidence of speciation in all of its stages - this in spite of the assumption that the process itself is so protracted that one cannot observe it. Consequently, as J. Huxley chided Dobzhansky for overstepping the bounds of biologically reality by declaring that the test of a true species was infertility, we can criticize Mayr for making assertions based not on scientific fact, but on self-citation of unfounded declarations.

But to continue the scenario, for Mayr, the emergence of different species is the consequence of a process that is always in motion and continually at play at the subspecific or intrapopulational level. As Mayr saw it, a subspecies is in actuality an "incipient" species poised to become a species in its own right when an econiche into which it could invade became available. Then, because of its different ecological circumstances, natural selection can mold it into something else. Consequently, as Mayr (Mayr, 1949) would reiterate:

Speciation is thus an adaptive process toward the most efficient utilization of the environment. An improvement of the environment will create new niches and will favor speciation; an impoverishment will lead to extinction. ( $p$. 284)

And from this perspective Mayr (Mayr, 1949) can reject by fiat and without evidence the possibility of any other mode of species formation, especially the models of so-called "instantaneous speciation" espoused, for instance, by de Vries, Bateson, and Goldschmidt:

Not individuals but populations are the units of evolution and such populations can drift apart decisively through an accumulation of small, often minute, genetic differences. Such gradual speciation is the norm while instantaneous speciation is the exception. (p. 285)

Ergo, echoing Dobzhansky's centralization of population genetics in the evolutionary process, there is only one way in which speciation can and normally does occur. What is interesting about this conception is that the individual is further disappeared from consideration, not only, as de Beer (de Beer, 1930) recognized, in terms of its developmental context, but also and in an odd way as the target of natural selection, in spite of the fact that natural selection is supposed to act on individuals and not on their "genes" or, as anti-group-selectionists would later maintain, populations or species

Nonetheless, Dobzhansky's population thinking greatly influenced the paleontologist Simpson (Simpson, 1944) in Tempo and Mode in Evolution, which he had begun in 1938 and left in the state he had reached when, in December 1942, he went to serve in WWII. His wife Ann Roe and the paleontologist E. H. Colbert of the American Museum of Natural History took the manuscript through its publication. Although still centralizing genetics and population genetics in particular, Simpson (Simpson, 1944) asserts that there are topics that only a paleontologist can address: namely, "evolutionary rates under natural conditions" (= "tempo"), and "the way, manner, or pattern of evolution," in other words "how populations became genetically and morphologically differentiated" (= "mode") (pp. xvii-xviii). In apparent demonstration of his attempt to synthesize paleontology with population genetics, Simpson declares further that, because his interest in this work "is to discuss the 'how' and...the 'why' of evolution, [and] not the 'what'," he will not dwell on either phylogeny or morphogenesis (ibid.). The "why" for Simpson's decision is clearly to demonstrate that, although paleontology apparently cannot contribute to understanding the process of species formation, it is not only amenable to population thinking but, because its "laboratory" encompasses organisms in the broad dimensions of time and space, it can provide insight into evolutionary questions that laboratory experiments cannot:

The paleontologist is given only phenotypes, and attempts to relate these to genotypes have so far had little success. But here genetics can provide him with the essential facts. One cannot directly study heredity in fossils, but one can assume that some, if not all, of its mechanisms were the same as those revealed by recent organisms in the laboratory...

On the other hand, experimental biology in general and genetics in particular have the grave defect that they cannot reproduce the vast and complex horizontal extent of the natural environment and, particularly, the immense span of time in which population changes really occur. They may reveal what happens to a hundred rats in the course of 10 years under fixed and simple conditions, but not what happened to a billion rats in the course of 10 million years under the fluctuating conditions of earth history. Obviously, the latter problem is much more important. (p. xvii)

Although one might infer some bitterness in this statement, Simpson nonetheless attempts a language steeped in population genetics, not just Dobzhansky's, but also 
Wright's (Wright, 1931, 1932), on whose shifting balance theory he bases much of his model of quantum evolution: rapid change between 2 different adaptive peaks. The irony here is that in his review of Tempo and Mode Wright (Wright, 1945) took such issue with the paleontologist for misrepresenting his shifting balance theory that Simpson thereafter downplayed discussion of population genetics. Perhaps, as a paleontologist, and thus someone whose work depends solely on preserved morphology, which, in turn informs taxonomic and phylogenetic hypotheses, Simpson should have plumbed his expertise to include a meaningful discussion of systematics (which Mayr also failed to do). But Simpson did not, no doubt because the population thinking demanded by Dobzhansky made species "fuzzy" entities and, because of being in states of constant motion, their identification, especially in the fossil record, artificial at best.

It might therefore seem a contradiction that Simpson's next treatise, The Principles of Classification and a Classification of Mammals (Simpson, 1945) dealt precisely with this topic, namely the identification and naming of species:

It is impossible to speak of the objects of any study, or to think lucidly about them, unless they are named. It is impossible to examine their relationships to each other their places among the vast, incredibly complex phenomena of the universe, in short to treat them scientifically, without putting them into some sort of formal arrangement...

Taxonomy is at the same time the most elementary and the most inclusive part of zoology, most elementary because animals cannot be discussed or treated in a scientific way until some taxonomy has been achieved, and most inclusive because taxonomy...eventually gathers together, utilizes, summarizes, and implements everything that is known about animals, whether morphology, physiological, psychological, or ecological.

...Emphasis of a particular one of these lines of approach has often obscured the existence of a common goal, and a myopic viewpoint has hidden from many students the final unity of the field of taxonomy...

...[O]ne of the most fundamental goals of modern biological research is comprehension of the way in which species arise, and we now find classifiers, experimental biologists, geneticists, ecologists, physiologists, statisticians... working together on this subject with full recognition of the fact that the common element in their problem is fundamentally taxonomic. (p. 1)
In a footnote to the last quote, Simpson (Simpson, 1945) writes, "The rise of this viewpoint is well demonstrated and exemplified by 'The new systematics,' edited by Julian Huxley, Oxford, 1940” (p. 1). Although Simpson (Simpson, 1944) listed this compendium in the bibliography of Tempo and Mode, his only direct reference to Huxley was to the latter scholar's discussion in Problems of Relative Growth (Huxley, 1932) of heterogony of antler size against body size in the deer Cervus elaphus (p. 177).

Simpson (Simpson, 1945) then proceeds to explain how modern taxonomy and systematics differed from these pursuits in the olden days, when species were identified by some often unstated morphological rule of thumb: "The aim is not merely to define populations in a better way...but also to explain their differences and resemblances and to correlate these with all the factors of organic evolution" (p. 2). This Simpson considers the first task of taxonomists, who he characterizes as having only just begun to think in this enlightened manner. The second task is "the study of phylogeny and the reconstruction of classification in accordance with it," which "extends to all levels of classification, but it is more important and, at present, more fruitful on higher levels" (p. 23).

In this last sentiment, Simpson embraces the notion first articulated by Darwin of a connection between classification and "genealogical relations" (= phylogenetic relationships). Of further interest is that Simpson had essentially completed the manuscript of Classification by late 1942, just before he went to serve in WWII. Its editing and fact checking under the direction of $\mathrm{E}$. H. Colbert took until late March 1944, with "only a few minor emendations" by Simpson before its publication on 5 October 1945 (Simpson, 1945) (p. ix). Considering that Simpson was writing Tempo and Mode and Classification in tandem and brought both essentially to final form by late 1942, it is astonishing how disassociated they are in their emphases. It is as if each had been written by a different author. For while reiterating Dobzhansky's focus on population genetics and going out of his way not to discuss morphology in Tempo and Mode, in Classification, Simpson (Simpson, 1945) the taxonomist/systematist recognizes that the reconstruction of phylogeny, and thus of the classification that derives from this endeavor [but which, however, he later states (p. 12) can never fully reflect phylogeny], perforce relies entirely on the study of morphology:

Phylogeny cannot be observed. It is necessarily an inference from observations that bear on it, sometimes rather distantly, and that can usually be interpreted in more than one way... 
The most direct, but unfortunately not the most useful, approach to the phylogeny of recent animals is through their genetics. The stream of heredity makes phylogeny; in a sense, it is phylogeny. Complete genetic analysis would provide the most priceless data for the mapping of this stream, although it would only exceptionally provide unequivocal and conclusive criteria...Aside from such rare cases, genotypic similarities and dissimilarities have to be interpreted phylogenetically in much the same way as phenotypic likenesses and differences... (p. 5)

...Obviously, extinct animals, so much more numerous than recent animals, are excluded [from genetic analysis]... (p. 6)

Genetical, physiological, embryological, and geographical data have been mentioned first, mainly because the orthodox classifier is likely to think of them last, but morphological data and paleontological data... always have been and....always will be the principal basis for the study of phylogeny... (p. 7)

After these assertions, Simpson disappoints in discussing the specifics of reconstructing phylogenetic relationships. Although stating the obvious - "Animals may resemble one another because they have inherited like characters, homology, or because they have independently acquired like characters, convergence" (p. 9) - he does not inform the reader how one can, or at least how he distinguishes between the 2 . Rather, he merely reiterates the accepted phenetic rule of thumb that animals with more homologous characters in common are more closely related and their common ancestry more recent than animals sharing fewer homologous characters. The likely reason the notion of greater overall similarity should be embraced without question - as it has been in molecular systematics since its resurgence in the early 1960s (Schwartz, 2005b, a; Schwartz and Maresca, 2006) - appears to be the following (Schwartz, in press-a).

With the expulsion by the triumvirate of "American" evolutionists of alternative theories of evolutionary change (both in tempo and mode) and their promoting their melding of Darwinism and population genetics as the only true representation of the process of evolution, the conception was that organisms are in a constant state of flux and change over time. Consequently, it was arbitrary to identify as separate species populations that were believed to have been phases in a forever-changing continuum and that only appeared to be discrete entities because taphonomic factors disrupted a fossil record that would otherwise portray a picture of continuity and smooth transformation. Thus this constant "dynamic flow" (p. 8) from one species to another produced lineages in which definitive boundaries between transforming species did not exist (Simpson, 1945). In turn, the longer 2 sister "species" shared a common and constantly changing lineage prior to their divergence (after which they continued on their separates paths of continual transformation), the more "homologous" features they would have in common. Ergo, it was the consequence of organisms and thus of their lineages being in states of constant Darwinian motion that permits the conclusion that the more similar organisms are, the longer their shared lineage "heritage", and thus the more recent their divergence into separate species. As such, while the Great Chain of Being taxonomist typically used the criterion of overall similarity to classify taxa on the belief that his sequencing of taxa reflected the work of a divine creator, the taxonomists/systematists of the "synthesis" used this criterion because the "method" of reconstructing phylogenetic propinquity was dictated by their assumed model of evolutionary change.

\section{Hennig, Simpson, and Mayr: a contrast of systematists}

With the publication of Hennig's (Hennig, 1950, 1966) "phylogenetic systematics", the complacency and routine of going about evolutionary business as usual was seriously threatened. Since there are many nuances and implications of his proposals that go beyond the scope of the discussion here, I will summarize the main relevant points.

Consider a hierarchy of relationships or hypotheses of propinquity: those between individuals of the same species (tokogenetic relationships), between 2 species, and between the smallest definable monophyletic groups (at least 3 species). However, even the most inclusive hypothesis of phylogenetic relationship - a hierarchically nested set of monophyletic groups -begins with hypothesized sister species.

Expanding on Dobzhansky's (and, although not stated, Mayr's) species concept: a species is a group of individuals at first spatially and then reproductively isolated from similar isolated groups. The consequence of these isolating mechanisms leads to distinct morphological gaps between these groups. Thus, in reverse historical order, now separated sister species would merge tokogenetically into one as they approached their last common ancestor or stem species.

Although generally assumed, degree of overall similarity is not a reflection of degree of relatedness. Rather, the sum total of features any organism possesses represents a history of retention of a sequence of character transformation events that likely correspond 
to the chronological series of hypothetical ancestors of hierarchically nested sets of sister taxa and monophyletic groups. Characters that are common to a wide range of taxa are for them primitive ("plesiomorphous") retentions from a relatively ancient common ancestor. Characters that are confined to groups of decreasing taxic inclusiveness are sequentially derived ("apomorphous") features and reflect a series of increasingly more recent common ancestors. Hypotheses of synapomorphy (shared apomorphies), not symplesiomorphy (shared pleisomorphies), likely more accurately reflect closeness of relatedness. When a more ancient taxon possesses character state "a" and a more recent taxon "al", their relative geological age should be the deciding factor between primitive (the more ancient) and derived (the more recent).

Because hypotheses of "primitive" and "derived" are relative within a hierarchy of monophyletic groups, symplesiomorphy at one level in the hierarchy was synapomorphy at a more ancient level.

Classification should reflect the hierarchical relationships of monophyletic groups.

Taxonomic rank of a monophyletic group should be determined by the age of the older member of that group (e.g. all groups that appear to have originated in the late Triassic would be assigned to the same rank).

These endeavors constitute "phylogenetic systematics".

Simpson (Simpson, 1961) and subsequently Mayr (Mayr, 1965, 1968, 1969) had very different reactions to Hennig's (Hennig, 1950) German publication. Interestingly, considering his (Simpson, 1949, 1952) attacks on other German evolutionists/systematists - first Goldschmidt and later with greater ferocity the paleontologist Otto Schindewolf - Simpson refers to Hennig only 3 times in his Principles of Animal Taxonomy and, in only one footnote, can a comment be construed as even slightly negative (Simpson, 1961).

First, Simpson (p. 6) agrees with Hennig on the point "that all science involves ordering and that systematics in that general sense is therefore coextensive with science." Second, he (p. 71) accepts Hennig's (1950) suggestion that the holomorph - all the characteristics of the individual throughout its life - should be the object of classification. And third, he (p. 96) makes clear that he understands the significance of recognizing levels in a hierarchy of nested sets of clades. Although Simpson also reveals an appreciation of the relative phylogenetic information content of ancestral versus advanced or specialized characters, he does not endorse Hennig's terms "plesiomorph" and "apomorph", which he considers "complex and idiosyncratic". Simpson's (p. 71) sole criticism is "that Hennig seems to be almost totally unaware of the vast body of English and American studies extremely pertinent to his theme."

Because Simpson writes at length on the history of taxonomy and classification and the scheme/s he adopts, it is surprising that he ignores or even purposefully omits discussion of Hennig's insistence on a direct translation of a hypothesized pattern of relatedness into a classification. That Simpson might have partially embraced this suggestion would, however, seem to be evident in his statement (p. 9) that "zoological classification is the ordering of animals into groups (or sets) on the basis of their relationships, that is, of associations by contiguity, similarity, or both." Simpson (Simpson, 1961) also does not address Hennig's program, "phylogenetic systematics". But he (p. 7) does provide his definition of systematics, which would appear at least in spirit to capture the essence of Hennig's concern in phylogenetic reconstruction: "the scientific study of the kinds and diversity of organisms and of any and all relationships among them."

Later in his monograph, Simpson turns to J. Huxley's (Huxley, 1940b) symposium and resultant volume, The New Systematics, which he (p. 64) dismisses as being both insignificant and lacking in any intellectual contribution to the field: "...from that book alone it is hardly possible to determine exactly what was new about its systematics or to draw up a formal statement of its principles, but it did make it clear that there was a ferment working in the field." Simpson further exhibits his disregard for Huxley's phrase by supplanting it with his own - "the new new systematics" - for which uses his own work as evidence of what systematics is and how it should be pursued. To make the point he lists the attributes he (pp. 65-66) considers relevant: "populations, not individuals, are the units of systematics and the things classified"; "populations are dynamic systems that evolve"; "taxonomic studies are always statistical in nature"; "taxa, at all levels, are not in principle defined by membership but by relationship"; "supraspecific taxa are delimited on the principle of monophyly"; "all taxa have a time dimension, which is pertinent to any definition or other consideration of them"; and "the construction of formal classifications of particular groups is an essential part and the useful outcome of taxonomic effort but is not the whose or even the focal aim... [which] is to understand the groupings and relationships of organisms in biological terms."

With regard now to Mayr, it is odd that in a work titled Systematics and the Origin of Species (Mayr, 1942) he only minimally discussed systematics in its broader context of phylogenetic reconstruction and taxonomy/classification. Why then - especially since he promoted himself as the systematist of the synthesis - did he wait well over 2 decades to produce Principles of Systematic Zoology (Mayr, 1969), in which he actually sought to discuss systematics? 
There are 2 likely contributing factors. By then Hennig's work was attracting serious attention, especially in the United States and Britain, and Mayr had a palpable dislike of Hennig's program, "phylogenetic systematics", being promoted as a well-constructed argument on how to pursue the reconstruction of evolutionary relationships and the relation between patterns of relatedness and classification (e.g. Mayr, 1965; Mayr, 1968). In addition, Simpson had published 2 monographs on the subject, The Principles of Classification and a Classification of the Mammals (Simpson, 1945) and Principles of Animal Taxonomy (Simpson, 1961). Although their titles emphasized taxonomy, their content, especially in the latter work, was clearly a discourse on systematics in general. Thus it would not be surprising if Mayr was concerned that Simpson might be seen as the real "systematist" of the "synthesis".

Whether either of these speculations is correct, it is the case that, in spite of the intellectual camaraderie that Dobzhansky, Mayr, and Simpson presented publicly in coordinating their monographs that formed the foundation of the "modern evolutionary synthesis" and defending their achievement against all heretics, the 3 disliked each other immensely. It is therefore noteworthy that more than 2 decades later Mayr (Mayr, 1969) maintains the "front" of civility by quoting Simpson's (Simpson, 1961) "modern redefinition of the term" systematics (p. 2): "systematics is the scientific study of the kinds and diversity of organism's and of any and all relationships among them." But he then offers as a better definition: “...or more simply, systematics is the science of the diversity of organisms" ( $\mathrm{p}$. 2). Although still emphasizing the centrality of populations within species and that the picture of evolution includes branching followed by divergence, Mayr presents himself as the broader minded and thus more informed systematist: "One of the major preoccupations of systematics is to determine, by comparison, what the unique properties of every species and higher taxon are" (p. 3). And it is from this perspective that he criticizes Hennig throughout rest of the monograph.

Mayr's objections are that Hennig and his disciples referred to their theoretical position as "the phylogenetic school" (p. 70); they demanded that classification mirror a hypothesized pattern of taxic relationships ("phylogenetic classification"); and they based the taxonomic ranks of clades on their geological or chronological ages. Mayr further objects to the "phylogenetic school" identifying itself thusly because, he maintains, the evolutionary process, and therefore phylogeny, consists not only of the branching or splitting of taxa, but also of the subsequent transformation of these new taxa. Consequently, he proposes the term cladism (Rensch, 1947; Cain and Harisson, 1960) to identify Hennig's conception, which he views as being concerned only with branching events, in part because he incorrectly (Schwartz, 2009) interprets Hennig as asserting that taxa remain static thereafter. As Mayr cautions, "Users of the recent literature are warned to look out for the misleading use of the term phylogeny by the cladists" (p. 70).

Mayr (pp. 72-73) continues his rejection of cladism - now the method of phylogenetic reconstruction - by citing Throckmorton's (Throckmorton, 1965) claims for Drosophilidae that "most of the diversification of this family has occurred by divergence from a single lineage that was itself changing slowly in time" (p. 233) and that "in most instances in Drosophila closely related species are complex mosaics of the characteristic of their nearest relative. They show individually very little that is unique to themselves. They show instead unique combinations of the characters found among other close relatives" (p. 227).

Yet is this not what one would expect of organisms whose existence as biologically integrated and functioning individuals is the result of a history of primitive retentions from a series of ancestors as well as of other features unique to them. Until the task of sorting primitive from derived features is done, one cannot know a priori how many apomorphies - one, 2, or more - will emerge as potentially unique to a species, sister taxa, and clades, and sister clades. Phylogenetic relationships cannot be predetermined by a systematist's imposed sense of how many features are required to define a species or a clade. A "unique" combination of primitive and derived features, to use T. Huxley's (Huxley, 1860) criticism of the Origin as an disorganized mass of facts, is nothing more than a "pemmican" of features, whose levels of phylogenetic significance - relative states of derivedness - need to be sorted out.

But Mayr's dislike of cladism continues, even though his arguments lack clarity of thought. While first stating correctly, I believe - that "the ordering of the diversity of nature is the foremost task of classification" (p. 74), Mayr then proclaims:

To use only one of the 2 processes leading to the diversification of groups - namely, branching - as evidence in the ordering procedure is self-defeating. The evolutionary taxonomist [namely, Mayr] agrees with the cladist in assuming that, usually, the more recently their phyletic lines separated, the more similar 2 taxa are. However, the evolutionary taxonomist also gives due weight in his classifications to any unequal divergence of the descendant lines. By deliberately ignoring these differences, the cladist is often forced to recognize taxa of very unequal value. (p. 74) (comment added) 
Did Mayr not begin with a criticism of cladistic classification? Yet he ventures into the realm of phylogenetic reconstruction by stating, incorrectly, that "the evolutionary taxonomist agrees with the cladist in assuming that, usually, the more recently their phyletic lines separated, the more similar 2 taxa are." No cladist, and certainly not Hennig, has embraced the notion that more recently divergent taxa will usually be more similar to each other. That is pure phenetics. Furthermore, such a statement can only result from adopting the Darwinian notion of organisms, and thus species, continually changing and in turn forming ever-changing lineages. As I pointed out earlier, by accepting this scenario, one is free to conclude that more recently divergent species will be more similar to each other than either will be to a lineage (and its current terminal species) that diverged some time in the past. This is not cladistic thinking, but it is consistent with Mayr's perspective. Thus for him to think that he and cladists are methodologically alike with regard to generating theories of relatedness not only reflects his lack of understanding Hennig's approach to phylogenetic reconstruction, but also demonstrates his belief that whatever he thinks and writes is unassailable and the ultimate word.

In the face of these inconsistencies, and of his subsequent but incorrect comparison of cladism and numerical taxonomy (p. 212), it might seen Quixotic that Mayr (pp. 213-214) inserts a discussion of "ancestral" and "derived" characters, but not without taking the opportunity to reject Hennig's terms "pleisomorphy" and "apomorphy". He does so on the grounds that these terms reflect a commitment to a particular evolutionary theory rather than being simple and self-explanatory. Interestingly, in this short discussion of the significance of, and of how to think about, distinguishing relative states of primitiveness and derivedness, Mayr is reminiscent of the British primatologist Le Gros Clark (Clark, 1959), who at the beginning of his monograph articulated clearly the importance of making and how to make these distinctions, but thereafter totally disregarded this endeavor and assumed the traditional phenetic approach to reconstructing evolutionary relationships.

\section{Concluding thoughts}

Terminating this exploration with Mayr's Principles of Systematic Zoology may seem too abrupt. Nevertheless, it should now be sufficiently clear that there has been a tension rather than an integrated relationship between systematics and the rest of evolutionary biology. This disconnect between disciplines that should be complementary is, I suggest, due largely to the "modern evolutionary synthesis" not being synthetic but focused exclusively on a particular kind of population thinking as well as to the "synthesizers" concerted efforts to reject, often without justification, alternative evolutionary theories. Although the idea of a synthesis was originally well intentioned (Jepsen, 1963) the bias that emerged and was subsequently enforced by Mayr throughout his long, Victorian-like reign over evolutionary biology, in the end did more intellectual harm to the field than good. Indeed, the long-lasting power and effect of the synthesis, not unlike the comic book and radio character, The Shadow, to "cloud men's minds" remains alive and so entrenched that self-appointed spokespersons for evolution such as Carroll (Carroll, 2006) continue to try to cram the square peg of developmental biology into the round hole of (neo)Darwinism. Further the belief that Darwin rejected Lamarckian use-disuse arguments and the architects of the synthesis completely expunged them from (neo)Darwinism belies the fact that use-disuse continues to be a common mode of evolutionary explanation, which is now being invoked even at the level of gene action (cf. Schwartz, 2001; Schwartz, 2007; Thorpe et al., 2007). The retort that by using the term "selection" one is not being Lamarckian (Thorpe et al., 2007) demonstrates just how deeply seated this fiction is.

This having been said, systematics and evolutionary biology need not remain uneasy bedfellows. Rather, inroads into developmental biology are increasingly emphasizing that organismal change, which might be synonymized with evolution, is not how it was imagined when the synthesis was enacted (see reviews in Schwartz, 1999; Maresca and Schwartz, 2006; Schwartz, 2010). Further, because of the interrelation between, for example, the physical properties of cells, signaling pathways, epigenetic effects on development, and consequently the origination of form, the false dichotomy that emerged in the 1980s, when morphology was declared unreliable in systematic studies while molecular approaches to systematics were infallible, is no longer sustainable (Schwartz, in press). With the realization that there is an integrated developmental continuum from the molecular through the morphological, morphology can resume a central position in systematic endeavors (Schwartz, in press) and, as is albeit slowly happening, lead to the generation of alternatives to Darwinism. But before this can occur, as cladists argued and debated in the 1970s and into the '80s about the assumptions underlying their endeavors, molecular systematists must also face their discipline's underlying assumptions, which, without concern for hypothesis testing, have been elevated to the status of fact.

It is a curious historical twist that had Darwin not rejected "sports" and "monstrosities" as representing windows on nature (Schwartz, 2005c), as Morgan later 
rejected the possibility that the bearers of the phenotypes derived from large-scale mutations could survive in nature (Schwartz, 2006b), and had the emphasis placed on evolution and development by T. Huxley (Huxley, 1863a), Mivart (Mivart, 1871), Bateson (Bateson, 1894), de Beer (de Beer, 1930), J. Huxley (Huxley, 1932, 1940b, 1942), Waddington (Waddington, 1940), Goldschmidt (Goldschmidt, 1940), and Schindewolf(Schindewolf, 1993) not been so unreservedly dismissed and even denigrated by the architects of the "modern evolutionary synthesis", we might now be witnessing a wider appreciation of the interplay between systematics, development, and evolutionary biology than currently exists amongst those who present themselves as evolutionary biologists and systematists. But while I would then have not had much to write about, I would also not be able to participate in what portends to be an exciting future for systematic studies.

\section{Acknowledgments}

I thank Francisco Vergara-Silva and Rasmus Winther for provoking me to attempt this overview, and Angelo Rosas López for translating the abstract.

\section{Literature cited}

Bateson, W. 1894. Materials for the Study of Variation, Treated with Especial Regard to Discontinuity in the Origin of Species. Macmillan, New York.

Cain, A. J., G. A. Harisson. 1960. Phyletic weighting. Proceedings of the Zoological Society London 131:1-31.

Carroll, S. B. 2006. The Making of the Fittest. W. W. Norton, New York. 301 p.

Clark, W. E. L. G. 1959. Antecedents of man. Harper and Row, New York. 374 p.

Darwin, C. 1859. On The Origin of Species by Means of Natural Selection, or the Preservation of Favored Races in the Struggle for Life. John Murray, London. 502 p.

Darwin, C. 1868. The Variation of Animals and Plants under Domestication. John Murray, London. 2 vols.

Darwin, C. 1871. The Descent of Man and Selection in Relation to Sex. John Murray, London. 2 vols.

Darwin, C. 1872. On The Origin of Species by Means of Natural Selection, or the Preservation of Favored Races in the Struggle for Life 6th edn. John Murray, London. 512 p.

Darwin, F. 1903. More Letters of Charles Darwin. John Murray, London. 494 p.

de Beer, G. R. 1930. Embryology and Evolution. Clarendon Press, Oxford. 116 p. de Beer, G. R. 1940. Embryology and taxonomy. In The New Systematics, J. Huxley (ed.). Clarendon Press, Oxford, p. 365-394.

de Vries, H. 1910a. Intracellular Pangenesis. Open Court, Chicago. 270 p.

de Vries, H. 1910b. The Mutation Theory. Open Court, Chicago. 2 vols.

Dobzhansky, T. 1935. A critique of the species concept in biology. Philosophy of Science, 2:344-355.

Dobzhansky, T. 1937. Genetics and the Origin of Species. Columbia University Press, New York. 364 p.

Dobzhansky, T. H. 1941. Genetics and the Origin of Species 2nd edn. Columbia University Press, New York. 446 p.

Fisher, R. A. 1930. The genetical theory of natural selection. Oxford University Press, Oxford. 272 p.

Gesner, K. 1551-1558. Historia Animalium, Zürich. 4 vols.

Goldschmidt, R. B. 1934. Lymantria. Bibliotheca Genetica 11:1180.

Goldschmidt, R. B. 1940. The Material Basis of Evolution. Yale University Press, New Haven. 436 p.

Grant, B. R., P. R. Grant. 2008. How and Why Species Multiply: the radiation of Darwin's finches. Princeton University Press, Princeton. 218 p.

Grant, P. R. 1999. Ecology and Evolution of Darwin's Finches. Princeton University Press, Princeton. 492 p.

Gregory, W. K. 1910. The order of mammals. Bulletin of the American Museum of Natural History 27:1-524.

Haeckel, E. 1868. The History of Creation: or the Development of the Earth and its Inhabitants by the Action of Natural Causes. A Popular Exposition of the Doctrine of Evolution in General, and that of Darwin, Goethe, and Lamarck in Particular. Appleton, New York. 2 vols.

Hennig, W. 1950. Grundzüge einer Theorie der Phylogenetischen Systematik. Deutscher Zentralverlag, Berlin. 370 p.

Hennig, W. 1966. Phylogenetic Systematics. University of Chicago Press, Chicago. 263 p.

Huxley, J. 1932. Problems of Relative Growth. Methuen, London. $312 \mathrm{p}$.

Huxley, J. 1940a. Introductory: towards the new systematics. In The New Systematics, J. Huxley (ed.). Clarendon Press, Oxford, p. 1-46.

Huxley, J. (1940b) The New Systematics. In. Clarendon Press, Oxford

Huxley, J. 1942. Evolution: The Modern Synthesis. Harper \& Brothers, New York. 645 p.

Huxley, T. H. (1860) Review of "The Origin of Species" In The Westminster Review, vol 17 (n.s.). p 22-79.

Huxley, T. H. 1863a. On the relation of Man to the lower animals. In Man's Place in Nature, T. H. Huxley (ed.). D. Appleton, New York: 71-138.

Huxley, T. H. 1863b. The sixth lecture on classification and on the characters of the principal groups of the animal kingdom. Medical Times and Gazette, (n.s.) 1:527-530. 
Huxley, T. H. 1863c. Evidence as to Man's Place in Nature. D. Appleton, New York. 184 p.

Huxley, T. H. 1869. An introduction to the classification of animals. John Churchill and Sons, London. 147 p.

Huxley, T. H. 1876. Lay Sermons, Addresses, and Reviews. D. Appleton, New York. 378 p.

Huxley, T. H. 1880. On the application of the laws of evolution to the arrangement of the Vertebrata and more particularly of the Mammalia. Proceedings of the Zoological Society London 1880:649-662.

Jepsen, G. L. 1949. Selection, 'orthogenesis,' and the fossil record. Proceedings of the American Philosophical Society 93:479-500.

Jepsen, G. L. 1963. Forward. In Genetics, Paleontology, and Evolution, G. L. Jepsen, G. G. Simpson, E. Mayr (eds.). Atheneum, New York: V-X.

Linnaeus, C. 1735. Systema naturae per regna tria naturae, secundum classes, ordines, genera, species cum characteribus, differentiis, synonymis, locis. Laurentii Salvii, Stockholm. 30 p.

Lovejoy, A. O. 1942. The Great Chain of Being. Harvard University Press, Cambridge, MA. 382 p.

Maresca, B., J. H. Schwartz. 2006. Sudden origins: a general mechanism of evolution based on stress protein concentration and rapid environmental change. The Anatomical Record (Part B: The New Anatomist) 289:38-46.

Mayr, E. 1942. Systematics and the Origin of Species. Columbia University Press, New York. 334 p.

Mayr, E. 1949. Speciation and systematics. In Genetics, Paleontology, and Evolution, G. L. Jepsen, G. G. Simpson, E. Mayr (eds.). Atheneum, New York, p. 281-298.

Mayr, E. 1965. Numerical phenetics and taxonomic theory. Systematic Zoology, 14:73-97.

Mayr, E. 1968. The role of systematics in biology. Science, 159:595-599.

Mayr, E. 1969. Principles of Systematic Zoology. McGraw-Hill, New York. 428 p.

Mivart, S. G. 1864. Notes on the crania and dentition of the Lemuridae. Proceedings of the Zoological Society of London 611-648.

Mivart, S. G. 1868. Notes on the osteology of the Insectivora. Journal of Anatomy and Physiology, 2:117-154.

Mivart, S. G. 1871. On the Genesis of Species. John Murray, London. $342 \mathrm{p}$.

Mivart, S. G. 1873. On Lepilemur and Cheirogaleus and on the zoological rank of the Lemuroidea. Proceedings of the Zoological Society of London 1873:484-510.

Mivart, S. G. 1882. On the classification and distribution of the Aeluroida. Proceedings of the Zoological Society London 1882:135-208

Morgan, T. H. 1903. Evolution and Adaptation. MacMillan, New York. 470 p.

Morgan, T. H. 1916. A Critique of the Theory of Evolution.
Princeton University Press, Princeton. 197 p.

Morgan, T. H. 1922. On the mechanism of heredity. Proceedings of the Royal Society (Biology) 94:162-197.

Morgan, T. H. 1935. The Scientific Basis of Evolution. W. W. Norton, New York.

Morgan, T. H., A. H. Sturtevant, H. J. Muller, C. B. Bridges. 1926. The Mechanism of Mendelian Heredity. Henry Holt, New York. 306 p.

Osborn, H. F. 1934. Aristogenesis, the creative principle in the origin of species. American Naturalist 68:193-235.

Ray, J. 1693. Synopsis Methodica Animalium Quadrupedum et Serpentini Generis. Samuel Smith, London. 336 p.

Rensch, B. 1947. Neuere Probleme der Abstammungslehre. Die transspezifische Evolution. Ferdinand Enke Verlag, Stuttgart. $436 \mathrm{p}$.

Schindewolf, O. 1936. Palaeontologie, Entwicklungslehre und Genetik. Bontrüager, Berlin. 108 p.

Schindewolf, O. 1993. Basic Questions in Paleontology: Geologic Time, Organic Evolution, and Biological Systematics. University of Chicago Press, Chicago. 467 p.

Schwartz, J. H. 1999. Sudden Origins: Fossils, Genes, and the Emergence of Species. John Wiley \& Sons, New York. 420 p.

Schwartz, J. H. 2001. Adaptation versus evolution. History and Philosophy of the Life Sciences 23:503-515.

Schwartz, J. H. 2005a. The Red Ape: Orangutans and Human Origins. Westview Pressx, Boulder, CO. 286 p.

Schwartz, J. H. 2005b. Molecular systematics and evolution. In Encyclopedia of Molecular Cell Biology and Molecular Medicine (EMCBMM), R. A. Meyer (ed.). Wiley-VCH Verlag, Weiheim. p. 515-540.

Schwartz, J. H. 2005c. Darwinism versus Evo-Devo: a late $19^{\text {th }} \mathrm{c}$. debate. In A Cultural History of Heredity III: $19^{\text {th }}$ and early $20^{\text {th }}$ Centuries S. Mueller-Wille, H.-J. Reinberger (eds.). Max Planck Institute for the History of Science, Berlin. p. 67-84.

Schwartz, J. H. 2006a. "Race" and the odd history of paleoanthropology. The Anatomical Record (Part B: The New Anatomist) 289B:225-240.

Schwartz, J. H. 2006b. Decisions, decisions: why Thomas Hunt Morgan was not the father of "evo-devo". Philosophy of Science 73:918-929.

Schwartz, J. H. 2007. The origins of human bipedalism: comment. Science 318:1065.

Schwartz, J. H. 2008. Cladistics. In Icons of evolution B. Regal (ed.). Greenwood Press, Westport CT, p. 517-544.

Schwartz, J. H. 2009. Reflections on systematics and phylogenetic reconstruction. Acta Biotheoretica, 57:295-305.

Schwartz, J. H. In press. Organismal biology, molecular systematics, and phylogenetic reconstruction. In Leaping Ahead: Advances in Prosimian Biology, J. Masters, M. Gamba, F. Génin (eds.). Springer Science, New York.

Schwartz, J. H. 2010. Organismal innovation. In Innovations in Cultural Systems: Contributions from Evolutionary 
Anthropology, M. J. O’Brien, S. J. Shennan (eds.). MIT Press, Cambridge, MA, p. 53- 67.

Schwartz, J. H., B. Maresca. 2006. Do molecular clocks run at all? a critique of molecular systematics. Biological Theory 1:1-15.

Simpson, G. G. 1944. Tempo and Mode in Evolution. Columbia University Press, New York. 237 p.

Simpson, G. G. 1945. The principles of classification and a classification of the mammals. Bulletin of the American Museum of Natural History 85:1-350.

Simpson, G. G. 1949. Essay-review of recent works on evolutionary theory by Rensch, Zimmermann, and Schindewolf. Evolution 3:178-184.

Simpson, G. G. 1952. Review of O. Schindewolf, Grundfragen der Paleontologie and Der Zeitfaktor in Geologie und Palaontologie. The Quarterly Review of Biology 27:388-389.

Simpson, G. G. 1961. Principles of Animal Taxonomy. Columbia University Press, New York. 247 p.

Thompson, D. A. W. 1917. On Growth and Form. Cambridge University Press, Cambridge, UK. 346 p.

Thorpe, S. K. S., R. L. Holder, R. H. Crompton. 2007. The origins of bipedalism: response. Science 318:1065.

Throckmorton, L. H. 1965. Similarity versus relationship in Drosophila. Systematic Zoology 14:221-235.

von Baer, K. E. 1828. Über Entwicklungsgeschicte der Thiere: Beobachtung und Reflexion. Bornträger, Königsberg. 264 p. Waddington, C. H. 1940. Organisers and genes. Cambridge University Press, Cambridge. 160 p.

Waddington, C. H. 1957. The genetic basis of the assimilated bithorax stock. Journal of Genetics 55:240-245.

Wallace, A. R. 1898. The Malay Archipelago: the land of the orang-utan and the birds of paradise. MacMillan and Co., London. 515 p.

Wright, S. 1931. Evolution in Mendelian Populations. Genetics 16:97-159.

Wright, S. 1932. The roles of mutation, inbreeding, crossbreeding and selection in evolution. Proceedings of the Sixth International Congress of Genetics 1:356-366.

Wright, S. 1945. Tempo and Mode in Evolution: a critical review (A review of Tempo and Mode in Evolution, by George Gaylord Simpson). Ecology 26:415-419. 